\title{
Mitochondrial Genome Resource of Phomopsis longicolla, a Fungus Causing Phomopsis Seed Decay in Soybean
}

\author{
Shuxian Li, ${ }^{1, \dagger}$ Youjin Deng ${ }^{2}$ \\ ${ }^{1}$ United States Department of Agriculture, Agricultural Research Service, Crop Genetics Research Unit, \\ Stoneville, MS 38776, U.S.A. \\ ${ }^{2}$ Center for Genomics and Biotechnology, Haixia Institute of Science and Technology, College of Life \\ Sciences, Fujian Agriculture and Forestry University, Fuzhou 350002, P.R. China
}

\section{Funding}

This work was partially supported by the United States Department of Agriculture, Agricultural Research Service, Crop Genetics Research Unit at Stoneville, MS (projects 6402-21220-012-00D and 606621220-014-00D).

\section{Keywords}

mitochondrial genome,

Phomopsis longicolla,

Phomopsis seed decay,

soybean pathogen

\section{Resource Announcement}

Phomopsis longicolla T. W. Hobbs (syn. Diaporthe longicolla) is a seed-borne fungal pathogen and the primary cause of Phomopsis seed decay (PSD) in soybean, Glycine max (L.) Merrill (Hepperly and Sinclair 1978; Hobbs et al. 1985; Li 2011; Li et al. 2010, 2015a). PSD severely reduces seed viability, alters seed composition, and increases frequencies of moldy and/or split beans, resulting in poor soybean seed quality worldwide.

Mitochondria play essential roles in eukaryotic cells for energy production, respiratory metabolism, and many other indispensable cellular processes. The characteristics of small size, high copy number, and high mutation rate of the fungal mitochondrial genome make it a suitable candidate for species identification and marker development (Avise et al. 1987; Deng et al. 2016). However, the mitochondrial genome of $P$. longicolla has not been well-studied. In this article we report the mitochondrial genome resource of $P$. longicolla.

$P$. longicolla isolate MSPL 10-6 was used in this study. We isolated this pathogen from fieldgrown soybean seed in Stoneville, Mississippi, U.S.A., in 2010 using the standard seed-plating procedure as previously reported ( $\mathrm{Li}$ et al. 2011, 2015b, 2017a). It was first identified using morphological characteristics according to Hobbs et al. (1985). The identification was further confirmed by analysis of the internal transcribed spacer region of rDNA amplified by polymerase chain reaction with primers ITS1 (5'-TCCGTAGGTGAACCTGCGG-3') and ITS4 (5'TCCTCCGCTTATTGATATGC-3') (Zhang et al. 1998). Sequences were analyzed using BLASTn at https://blast.ncbi.nIm.nih.gov/Blast.cgi. A cut-seedling inoculation method was used to test the pathogenicity of the pathogen (Li 2018). MSPL 10-6 is one of the most aggressive isolates causing PSD in soybean and has been used in previous studies to identify new sources of resistance to the disease (Li et al. 2011, 2015b, 2017a).

Genomic DNA was extracted using a Qiagen DNeasy Plant Mini kit (Qiagen, Valencia, CA) after growth of $P$. longicolla MSPL 10-6 isolate in potato dextrose broth (Difco Laboratories,

${ }^{\dagger}$ Corresponding author: S. Li; shuxian.li@usda.gov

The author(s) declare no conflict of interest.

Accepted for publication 2 November 2020. 
Table 1. A list of single nucleotide polymorphisms and insertions/deletions identified in the mitochondrial genome of Phomopsis longicolla isolate MSPL 10-6

\begin{tabular}{|c|c|c|c|c|c|}
\hline Reference accession ${ }^{a}$ & MSPL 10-6 accession & $\begin{array}{l}\text { Position } \\
\text { (reference) }\end{array}$ & $\begin{array}{l}\text { Nucleotide in } \\
\text { reference }\end{array}$ & $\begin{array}{l}\text { Nucleotide in } \\
\text { MSPL 10-6 }\end{array}$ & $\begin{array}{c}\text { Position } \\
\text { (MSPL 10-6) }\end{array}$ \\
\hline KP137411.1 & MT527962 & 8,592 & $\mathrm{G}$ & $\mathrm{T}$ & 7,122 \\
\hline KP137411.1 & MT527962 & 9,065 &.$^{b}$ & TGAC & 7,596 \\
\hline KP137411.1 & MT527962 & 11,965 & $A$ & . & 10,501 \\
\hline KP137411.1 & MT527962 & 12,082 & $\mathrm{~T}$ & $A$ & 10,618 \\
\hline KP137411.1 & MT527962 & 12,083 & $\mathrm{~T}$ & $A$ & 10,619 \\
\hline KP137411.1 & MT527962 & 29,719 & $\mathrm{C}$ & $G$ & 28,254 \\
\hline KP137411.1 & MT527962 & 34,225 & $\mathrm{~T}$ & . & 32,759 \\
\hline KP137411.1 & MT527962 & 36,054 & $\mathrm{~T}$ & $\mathrm{C}$ & 34,588 \\
\hline KP137411.1 & MT527962 & 36,242 & $G$ & . & 34,775 \\
\hline KP137411.1 & MT527962 & 36,953 & $A$ & . & 35,485 \\
\hline KP137411.1 & MT527962 & 38,144 & . & CAG & 36,677 \\
\hline KP137411.1 & MT527962 & 40,176 & . & AGTC & 38,713 \\
\hline KP137411.1 & MT527962 & 40,502 & $\mathrm{~T}$ & C & 39,042 \\
\hline KP137411.1 & MT527962 & 40,503 & $\mathrm{~T}$ & $\mathrm{G}$ & 39,043 \\
\hline KP137411.1 & MT527962 & 40,505 & . & $\mathrm{T}$ & 39,046 \\
\hline KP137411.1 & MT527962 & 40,507 & $\mathrm{C}$ & $A$ & 39,048 \\
\hline KP137411.1 & MT527962 & 40,511 & . & GTA & 39,053 \\
\hline KP137411.1 & MT527962 & 40,533 & . & CTA & 39,078 \\
\hline KP137411.1 & MT527962 & 40,536 & . & AGTC & 39,084 \\
\hline KP137411.1 & MT527962 & 41,287 & . & TGAC & 39,839 \\
\hline KP137411.1 & MT527962 & 41,290 & . & GTA & 39,846 \\
\hline KP137411.1 & MT527962 & 41,336 & . & CTA & 39,895 \\
\hline KP137411.1 & MT527962 & 41,339 & . & AGTC & 39,901 \\
\hline KP137411.1 & MT527962 & 51,537 & . & $A$ & 50,086 \\
\hline KP137411.1 & MT527962 & 52,297 & C & $A$ & 52,162 \\
\hline KP137411.1 & MT527962 & 52,300 & $\mathrm{G}$ & $A$ & 52,165 \\
\hline KP137411.1 & MT527962 & 53,083 & . & GG & 52,949 \\
\hline KP137411.1 & MT527962 & 53,085 & $\mathrm{~T}$ & $A$ & 52,952 \\
\hline KP137411.1 & MT527962 & 53,118 & . & $\mathrm{CCC}$ & 52,986 \\
\hline
\end{tabular}

a Type strain of $P$. longicolla ATCC 60325 .

b Period (.) indicates absent or deletion.

Detroit, MI) for 4 days under $12-\mathrm{h}$ light-and-dark cycles at $24^{\circ} \mathrm{C}$. The quality of DNA was assessed by $1 \%$ agarose gel electrophoresis, and DNA was quantified using a Nanodrop 1000 and a Qubit version 2.0 fluorometer. Two sequencing libraries were generated. The no-gel mate-pair libraries were made with the Nextera Mate-Pair Sample Preparation kit (Illumina, San Diego, CA), and the paired-end libraries were generated with the TruSeq DNA PCR-Free Sample Preparation kit (Illumina) as described by the manufacturer. Sequencing of the libraries was performed in separate lanes on an Illumina HiSeq 2500 sequencer using a TruSeq SBS sequencing kit (version 3, Illumina) in the Genomics Core Facility, Purdue University, West Lafayette, Indiana, as reported previously ( $\mathrm{Li}$ et al. 2017b). The mate-pair library generated $72,216,734$ reads with a total of 8.2 billion bp and average length of $113 \mathrm{bp}$, representing 128- 
fold coverage. The paired-end library produced $63,763,666$ reads with a total of 6.2 billion and average length of $97 \mathrm{bp}$, representing 97 -fold coverage.

The mitochondrial genome of $P$. longicolla was assembled using the program Velvet 1.2.03 (Zerbino and Birney 2008). Protein-coding and rRNA genes as well as introns were annotated automatically using the online program MFannot (http://megasun.bch.umontreal.ca/cgi-bin/ mfannot/mfannotlnterface.pl) with the mold genetic code. The types of intron-encoded open reading frames were identified by searching the National Center for Biotechnology Information (NCBI) conserved domain database (Deng et al. 2018). The dispersed and inverted repeat sequences in the mitochondrial DNA were identified by performing self-BLAST through BLASTn search $\left(E<10^{-10}\right)$. Analysis of single nucleotide polymorphisms (SNPs) and insertions/ deletions (InDels) was conducted using MUMmer 4.x (Marçais et al. 2018). A SNP detection script was written using the "nucmer", "delta-filter", and "show-snp" components of MUMmer.

The circular mitochondrial genome of $P$. longicolla isolate MSPL $10-6$ is 53,646 bp long with GC content of $34.27 \%$. It encodes 14 common protein genes, 23 tRNA genes, and two rRNA genes. Ten introns were identified: four introns in cox1 and one intron in each cox2, nad5, atp6, $\mathrm{rnl}$, nad1, and cob. BLAST analysis against available sequence data at NCBI showed that the mitochondrial genome sequence of $P$. longicolla isolate MSPL $10-6$ is $99.81 \%$ identical to the $P$. Iongicolla type strain ATCC 60325 (accession KP137411.1) and 95.88 and $95.75 \%$ identical to Sordaria macrospora k-hell (accession XM 003342344) and Diaporthe phaseolorum (accession AY779295), respectively. By comparing two identical mitochondrial genome sequences of $P$. longicolla (accessions KP137411.1 and NC_027509) available at GenBank, 45 SNPs and InDels were identified (Table 1).

The mitochondrial genome sequence of $P$. longicolla isolate MSPL 10-6 will be useful for further investigation of the genetic basis of seed-borne pathogens causing seed disease in soybean, and it provides a valuable resource for molecular marker development, which will aid in detection of the pathogen, disease monitoring, and improvement of control strategies for PSD.

The mitochondrial genome of $P$. longicolla isolate MSPL 10-6 has been deposited in the NCBI GenBank database under accession number MT527962.

\section{Acknowledgments}

We are grateful to Phillip SanMiguel at Purdue Genomics Core Facility for sequencing. Mention of trade names or commercial products in this publication is solely for the purpose of providing specific information and does not imply recommendation or endorsement by the United States Department of Agriculture. USDA is an equal opportunity provider and employer.

\section{Literature Cited}

Avise, J. C., Arnold, J., Ball, R. M., and Bermingham, E. 1987. Intraspecific phylogeography: The mitochondrial DNA bridge between population genetics and systematics. Annu. Rev. Ecol. Syst. 18:489-522.

Deng, Y., Hsiang, T., Li, S., Lin, L., Wang, Q.-F., Chen, Q., Xie, B., and Ming, R. 2018. Comparison of the mitochondrial genome sequences of six Annulohypoxylon stygium isolates suggests short fragment insertions as a potential factor leading to larger genomic size. Front. Microbiol. 9:2079.

Deng, Y., Zhang, Q., Ming, R., Lin, L., Lin, X., Lin, Y., Li, X., Xie, B., and Wen, Z. 2016. Analysis of the mitochondrial genome in Hypomyces aurantius reveals a novel twintron complex in fungi. Int. J. Mol. Sci. 17:1049.

Hepperly, P. R., and Sinclair, J. B. 1978. Quality losses in Phomopsis-infected soybean seeds. Phytopathology 68:1684-1687.

Hobbs, T. W., Schmitthenner, A. F., and Kuter, G. A. 1985. A new Phomopsis species from soybean. Mycologia 77:535-544.

Li, S. 2011. Phomopsis seed decay of soybean. Pages 277-292 in: Soybean - Molecular Aspects of Breeding. A. Sudaric, ed. Intech, Vienna, Austria.

$\mathrm{Li}, \mathrm{S}$. 2018. Development of a seedling inoculation technique for rapid evaluation of soybean for resistance to Phomopsis longicolla under controlled conditions. Plant Methods 14:81.

Li, S., Chen, P., and Hartman, G. L. 2015a. Phomopsis seed decay. Pages 47-48 in: Compendium of Soybean Diseases and Pests, 5th Ed. G. L. Hartman, J. C. Rupe,
E. J. Sikora, L. L. Domier, J. A. Davis, and K. L. Steffey, eds. APS Press, St. Paul, MN.

Li, S., Darwish, O., Alkharouf, N., Musungu, B., and Matthews, B. F. 2017b. Analysis of the genome sequence of Phomopsis longicolla: A fungal pathogen causing Phomopsis seed decay in soybean. BMC Genomics 18:688.

Li, S., Hartman, G. L., and Boykin, D. 2010. Aggressiveness of Phomopsis longicolla and other Phomopsis spp. on soybean. Plant Dis. 94:1035-1040.

Li, S., Rupe, J., Chen, P., Shannon, G., Wrather, A., and Boykin, D. 2015b. Evaluation of diverse soybean germplasm for resistance to Phomopsis seed decay. Plant Dis. 99:1517-1525.

Li, S., Sciumbato, G., Rupe, J., Shannon, G., Chen, P., and Boykin, D. 2017a. Evaluation of commercial soybean cultivars for reaction to Phomopsis seed decay. Plant Dis. 101:1990-1997.

Li, S., Smith, R., and Nelson, R. 2011. Resistance to Phomopsis seed decay identified in maturity group V soybean plant introductions. Crop Sci. 51:2681-2688.

Marçais, G., Delcher, A. L., Phillippy, A. M., Coston, R., Salzberg, S. L., and Zimin, A. 2018. MUMmer4: A fast and versatile genome alignment system. PLOS Comput. Biol. 14:e1005944.

Zerbino, D. R., and Birney, E. 2008. Velvet: Algorithms for de novo short read assembly using de Bruijn graphs. Genome Res. 18:821-829.

Zhang, A. W., Hartman, G. L., Riccioni, L., and Pedersen, W. L. 1998. Molecular identification and phylogenetic grouping of Diaporthe phaseolorum and Phomopsis longicolla isolates from soybean. Phytopathology 88:1306-1314. 